\title{
KEMAMPUAN MAHASISWA UNIVERSITAS NEGERI MEDAN DALAM MENGGUNAKAN BAHASA BAKU DAN TIDAK BAKU
}

\author{
Fadhillah Rahma Purba ${ }^{1)}$, Gresia Palentina ${ }^{2)}$, Fitriani Lubis ${ }^{3)}$ \\ ${ }^{123}$ FMIPA, Universitas Negeri Medan \\ Pos-el: fadraprb1204@gmail.com, gresiafalen15@gmail.com.
}

\begin{abstract}
Abstrak
Pada artikel ini mendeskripsikan hasil penelitian dari kemampuan dalam penggunaan bahasa baku pada kalangan mahasiswa Universitas Negeri Medan. Penelitian ini dilatarbelakangi oleh banyaknya penulisan mahasiswa yang mengerti arti pengertian dari bahasa baku tetapi tidak memahami penggunaaan bahasa baku yang sesuai dengan kaidah kebahasaan. hal ini terlihat dari mahasiswa yang masih sering sekali menggunakan bahasa non baku dalam menulis laporan dalam perkuliaha. Tujuan penelitian ini dilakukan untuk mengetahui kemampuan mahasiswa Universitas Negeri Medan dalam berbahasa yang baku, yang menjadi fokus pada penelitian ini adalah pemahaman mahasiswa dalam penulisan bahasa baku yang sesuai dengan kaidah kebahasaan. Hasil penelitian menunjukan hanya hanya $60 \%$ mahasiswa yang memahami bahasa baku yang sesuai kaidah kebahasaan dan masih terdapat $40 \%$ mahasiswa yang tidak memahami bahasa baku yang sesuai dengan kaidah kebahasaan. Hasil ini menunjukan bahwa kemampuan menggunakan bahasa baku pada kalangan mahasiswa Universitas Negeri Medan masih rendah dan perlu adanya peningkatan minat dalam meningkatkan kebiasaan menulis bahasa baku.

Kata Kunci: Pemahaman, Kaidah kebahasaan, bahasa baku
\end{abstract}

\section{Abstract}

This article describes the results of the research on the ability to use standard language among students at the State University of Medan. This research is motivated by the number of writing students who understand the meaning of standard language but do not understand the use of standard language in accordance with linguistic rules. this can be seen from students who still frequently use non-standard language in writing reports in lectures. The purpose of this study was conducted to determine the ability of students at the State University of Medan in standard language, the focus of this study was the understanding of students in writing standard language in accordance with linguistic principles. The results showed that only $60 \%$ of students understood the standard language according to the rules. language and there are still $40 \%$ of students who do not understand standard language in accordance with linguistic rules. These results indicate that the ability to use standard language among students at the State University of Medan is still low and there needs to be an increase in interest in improving the habit of writing standard language. Keywords: Understanding, language rules, standard language 


\section{PENDAHULUAN}

Bahasa menjadi salah satu cara untuk mengungkapkan ide, gagasan, perasaan dan keinginan terhadap sesuatu hal yang baik secara lisan maupun secara tulis. Selain itu, bahasa juga bersifat komunikatif yang memiliki fungsi sebagai cara melakukan komunikasi agar tercapainya suatu maksud yang ingin disampaikan kepada orang lain. Menurut Pranowo (2015) berbahasa secara komunikatif berarti menggunakan bahasa sesuai dengan fungsi-fungsi komunikasi, agar mudah dipahami oleh pendengar atau pembaca. Penggunaan bahasa dapat berubah seiring perkembangan individu dan lingkungan individu dalam penggunaan bahasa.

Bahasa meruapakan simbol atau ciri khas dari suatu negara ataupun wilayah, karena bahasa merupakan unsur vital sebagai alat komunikasi paling utama. Dalam melakukan interaksi atau hubungan sosial dengan sesama di masyarakat, setiap orang membutuhkan bahasa. Bahasa sangat beragam di dunia ini, karena setiap negara mepunyai bahasa yang berbeda satu dengan yang lain, bahkan bahasa dapat membedakan antara negara yang satu dengan negara yang lainny, begitu juga daerah yang satu dengan daerah lainnya. Negara Indonesia menggunakan bahasa Indonesia sebagai bahasa umum atau utama dalam bernegara, berbeda dengan negara Amerika yang menggunakan bahasa Inggris dalam bernegara. Jadi, bahasa juga dapat menjadi ciri dari suatu negara.

Pemahaman tentang kemampuan berbahasa Indonesia baku dan tidak baku sangatlah penting. Dengan pemahaman tentang hal tersebut, dapat dilakukan tindak lanjut yang relevan. Jika kemampua npemahaman yang rendah, dapat dilakukan pembinaan yang intensif, baik secara terprogram, yaitu melalui mata kuliah yang substansinya membekalinya agar dapat berbahasa Indonesia baku sesuai dengan tuntutan kaidah kebahasaan itu maupun pembinaan secara insidental, yaitu melalui pelatihan. Sementara itu, jika kemampuan pemahaman bahasa baku tinggi, dapat dilakukan penguatan. Penggunaan kata baku dalam karya ilmiah dapat diteliti sekurang-kurangnya dari tiga aspek, yaitu (1) ejaan (aspek fonologis), (2) bentuk kata (aspek morfologis) dan (2) maknanya (semantis).

Fungsi bahasa menurut Abidin, dkk (2010:3) menjelaskan bahwa fungsi utama bahasa adalah sebagai media 
komunikasi, tetapi selain sebagai media komunikasi bahasa juga memiliki fungsi lain yaitu: (1) Fungsi ekspresif Bahasa dapat digunakan untuk mengekspresikan ide, gagasan, dan pengelaman. Contohnya dalam puisi. Pengarang mengeksperikan ide, gagasan dan pengalamanya dengan bahasa yang ditulis per bait yang disebut puisi. (2) Fungsi estetis Bahasa sebagai media yang indah untuk menyampaikan pesan. Fungsi estetis ini biasa diwujudkan dalam bentuk karya sastra. (3) Fungsi informatif, artinya bahasa dapat digunakan untuk menginformasikan sesuatu kepada orang lain. (4) Alat fungsional, artinya bahasa dapat dijadikan sebagai alat untuk mencapai tujuan tertentu.

Istilah bahasa baku telah dikenal oleh masyarakat luas, namun pengenalan istilah tidak menjamin bahwa mereka memahami secara komprehensif konsep dan makna istilah itu sendiri. Hal ini dapat menjadi bukti bahwa masih banyak masyarakat yang berpendapat bahwa bahasa baku sama dengan bahasa yang baik dan benar.Makna dari kata baku sendiri tampaknya tidak dipahami secara benar,apalagi makna dar bahasa baku. Hal ini dapat disebabkan oleh keengganan orang-orang atau masyarakat dalam mencari makna istilah baku dan bahasa baku didalam kamus umum ataupun kamus istilah linguistik.

Bahasa baku merupakan bahasa yang menjadi pokok atau yang menjadi dasar ukuran atau standar. Sedangkan bahasa Indonesia baku adalah ragam bahasa Indonesia yang menjadi pokok,yang menjadi standar ukuran atau yang menjadi standar. Dengan demikinan pengertian bahasa non baku dapat diartikan sebagai bahasa yang tidak menjadi pokok,yang tidak menjadi dasar ukuran atau tidak menjadi standar. Jadi bahasa Indonesia Non baku adalah ragam bahasa Indonesia yang tidak menjadi pokok, tidak menjadi dasar ukuran, atau yang tidak menjadi standar.

Bahasa baku adalah bentuk bahasa yang biasa memakai kata-kata atau ungkapan,struktur kalimat,ejaan atau dan pengungkapan yang biasa dipakai oleh mereka yang berpendidikan. Sedangkan bahasa non baku adalah bentuk bahasa yang biasa memakai kata-kata atau ungkapan,struktur kalimat,ejaan,dan pengucapan yang biasa dipakai oleh mereka yang kurang berpendidikan dan yang biasa beraktivitas dalam lingkungan tidak resmi.

Istilah bahasa baku dalam bahasa Indonesia atau standard language dalam 
bahasa Inggris, dalam dunia ilmu bahasa atau linguistik pertama sekali diperkenalkan oleh Vilem Mathesius pada 1926. Ia termasuk pencetus Aliran Praha atau The Prague School. Pada 1930, B. Havranek dan Vilem Mathesius merumuskan pengertian bahasa baku itu. Mereka berpengertian bahwa bahasa baku sebagai bentuk bahasa yang telah dikodifikasi, diterima dan difungsikan sebagai model atau acuan olehmasyarakat secara luas. Bahasa baku adalah bahasa standar (pokok) yang kebenaran dan ketetapannya telah ditentukan oleh negara. Baku berarti bahasa tersebut tidak dapat berubah setiap saat. kehidupan sehari-hari lebih banyak orang yang menggunakan bahasa tidak baku dan sesuka hati. Berdasarkan pengertian di atas, bahasa baku adalah bahasa standar yang benar dan digunakan oleh suatu masyarakat pada suatu negara. Bahasa baku atau standar itu harus diterima dan berterima bagi masyarakat bahasa.

Halim (1980) mengatakan bahwa bahasa baku adalah ragam bahasa yang dilembagakan dan diakui oleh sebagian masyarakat, dipakai sebagai ragam resmi dan sebagai kerangka rujukan norma bahasa dan penggunaannya. Pei dan Geynor (1954: 203) menggatakan bahwa bahasa baku adalah dialek suatu bahasa yang memiliki keistimewaan sastra dan budaya melebihi dialek-dialek lainnya, dan disepakati penutur dialek-dialek lain sebagai bentuk bahasa yang paling sempurna.

Bahasa Indonesia baku merupakan salah satu ragam bahasa Indonesia yang bentuk bahasanya telah dikodifikasi. Oleh karena itu bahasa Indonesia baku merupakan ragam bahasa Indonesia yang menjadi pokok, yang menjadi dasar ukuran atau yang menjadi standar.

Bahasa Indonesia Tidak Baku Bahasa Indonesia tidak baku adalah salah satu ragam bahasa Indonesia yang tidak dikodifikasi, tidak diterima dan tidak difungsikan sebagai model masyarakat Indonesia secara luas, tetapi dipakai oleh masyarakat secara khusus. Oleh karena itu bahasa Indonesiat tidak baku merupakan ragam bahasa Indonesia yang tidak menjadi pokok, yang tidak menjadi dasar ukuran atau yang tidak menjadi standar.

Bahasa Indonesia baku memiliki empat fungsi yaitu : (1) bahasa Indonesia baku berfungsi sebagai pemersatu bangsa, (2) bahasa Indonesia baku berfungsi sebagai penenda kepribadian, (3) bahasa Indonesia baku berfungsi sebagai penambah wibawa, (4) bahasa Indonesia baku berfungsi sebagai kerangka acuan. 
Bahasa Indonesia baku di pakai di dalam beberapa konteks yaitu: (1) dalam komunikasi resmi, (2) dalam wacana teknis, (3) dalam pembicaraan di depan umum, (4) dalam pembicaraan dengan orang yang dihormati.

Ciri-ciri bahasa Indonesia baku, secara umum dapat diketahui bahwa bahasa Indonesia baku mempunyai tiga ciri yaitu: (1) memiliki keunggulan wilayah dan waktu pengguanaan, (2) kemantapan dinamis, dan (3) cendikia. Dalam hal ini, kemantapan dinamis berarti bahwa kaidah bahasa Indonesia baku relative tetap serta tidak berubah setiap saat. Ciri cendikia berarti bahwa bahasa Indonesia baku mencerminkan cara berfikir yang teratur,logis,dan sistematis.

\section{METODE PENELITIAN}

Pada penelitian ini Penulis menggunakan metode pendekatan kualitatif deskriptif. Sugiono (2016) menjelaskan bahwa penelitian kualitatif adalah metode penelitian yang digunakan untuk meneliti pada kondisi obyek yang alamiah dimana pengambilan sampel data dilakukan secara purposive sampling. Penelitian kualitatif deskriptif berarti data yang telah dikumpulkan berbentuk kata- kata atau gambar, sehingga tidak ditemukan angka.

Pada artikel ini sampel yang digunakan adalah Mahasiswa Uiversitas Negeri Medan. Sampel yang digunakan penulis pada penelitian ini berjumlah 15 orang dengan jurusan yang berbeda-beda namun telah ditentukan siapa yang dapat menjadi sampel. Instrumen penelitian yang digunakan adalah lembar penelitian seperti angket online yang dibagikan pada responden yang menjadi sampel penelitian. Pada angket yang penulis bagikan kepada responden, berisi pertanyaan mengenai bahasa baku dan tidak baku. Penulis juga memberikan 13 kata baku dan tidak yang harus responden bedakan. Pengumpulan data dilakukan dengan cara mengumpulkan angket yang telah diisi secara online.

\section{HASIL DAN PEMBAHASAN}

Berikut ini adalah hasil analisis terhadap kemampuan mahasiswa Universitas Negeri Medan dalam membedakan bahasa baku dan tidak baku: 
Tabel 1.1

Hasil Angket Pengetahuan Bahasa

Baku dan Tidak Baku

\begin{tabular}{|c|c|c|}
\hline \multirow{2}{*}{ Kata } & \multicolumn{2}{|c|}{$\begin{array}{c}\text { Sampel yang } \\
\text { Menjawab }\end{array}$} \\
\hline & Baku & $\begin{array}{l}\text { Tidak } \\
\text { Baku }\end{array}$ \\
\hline Bosan & 15 Orang & - \\
\hline Cinderamata & 8 Orang & 7 Orang \\
\hline Efektivitas & 13 Orang & 2 Orang \\
\hline Diagnosis & 8 Orang & 7 Orang \\
\hline Analisis & 10 Orang & 5 Orang \\
\hline Berpikir & 5 Orang & 10 Orang \\
\hline Imbau & 9 Orang & 6 Orang \\
\hline Korsleting & 11 Orang & 4 Orang \\
\hline Menteri & 15 Orang & - \\
\hline Merek & 10 Orang & 5 Orang \\
\hline Notula & 8 Orang & 7 Orang \\
\hline Persepsi & 15 Orang & - \\
\hline Tobat & 8 Orang & 7 Orang \\
\hline
\end{tabular}

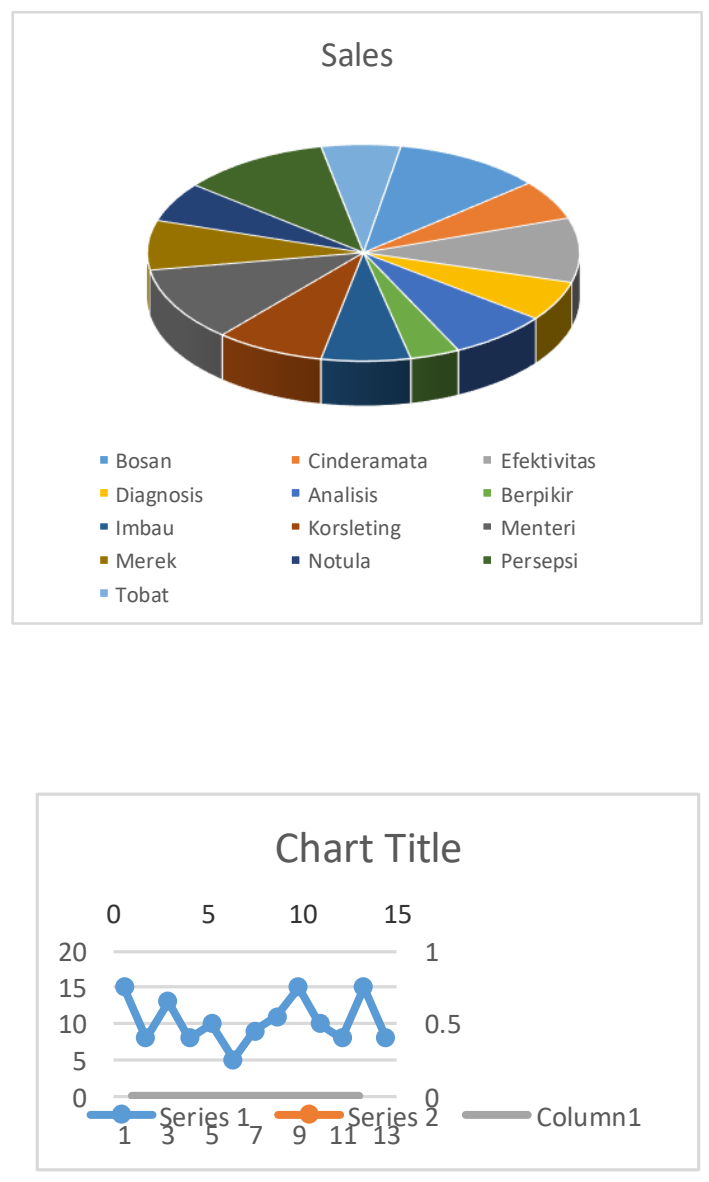

Hasil angket yang disebarkan kepada 15 sampel mahasiswa Universitas Negeri Medan menunjukkan bahwa kemampuan mahasiswa untuk membedakan antara bahasa baku dan tidak baku masih tergolong rendah. Dari 13 Kata baku dan tidak baku, hampis sebagian kata baku dan tidak baku yang sulit dibedakan oleh mahasiswa. Kata baku yang mudah dibedakan adalah “ Bosan dan Bosen", "Manteri dan Mentri”, "Presepsi dan Presepsi" dan yang paling banyak mahasiswa salah menjawab adalah pada kata " Berpikir dan Berfikir”. Dapat dilihat bahwa mahasiswa 
beranggapan bahwa apa yang menurut mereka kata baku adalah kata yang mereka biasa ucapkan dalam kehidupan sehari-hari. Hal ini menunjukkan bahwa sudah mulai hilang kemampuan siswa dalam memilih bahasa Indonesia yang baik dan benar. Hilangnya kata baku tersebut disebabkan oleh globalisasi yang mana masuknya beberapa bahasa Asing ke Indonesia.

Semakin lama akan terlihat jelas bahwa kemampuan mahasiswa dalam penggunaan kata baku sudah menurun akibat adanya globalisasi. Apabila terus dibiarkan maka kemungkinan bahasa nasional akan tergeser dikarenakan kehadiran bahasa asing tersebut. Untuk menghindari hal tersebut, seharusnya masyarakat khususnya mahasiswa harus melestarikan kecintaan terhadap bahasa indonesia sebagai bahasa nasional. Mahasiswa sebagai generasi muda yang akan memberikan perubahan kepada bangsa harusnya menggunakan bahasa nasional dengan baik dan benar. Sebenarnya, kata-kata yang dicantumkan oleh penulis diatas tersebut merupakan kata-kata yang sudah biasa didengar oleh banyak orang dan dalam kehidupan sehari-hari. Namun kenyataannya masih banyak mahasiswa yang tidak dapat membedakan yang mana kata baku dan tidak baku.

\section{SIMPULAN}

Berdasarkan hasil penelitian yang telah dijelaskan diatas, dapat disimpulkan bahwa kata baku merupakan kata yang terdapat dalam Kamus Besar Bahasa Indonesia, sedangkan kata tidak baku adalah kata bahasa Indonesia yang telah tercampur cara pengucapannya dengan bahasa asing. Kata baku dalam bahasa Indonesia akan menjadi kokoh apabila selalu digunakan dalam komunikasi sehari-hari. Namun, saat ini banyak mahasiswa yang kurang kemampuannya tentang bahasa baku sebagai dasar bahasa Indonesia yang baik dan benar.

\section{DAFTAR PUSTAKA}

E. Zaenal Arifin, S. Amran Tasai. (2010). Cermat Berbahasa Indonesia untuk Perguruan Tinggi. Jakarta: Akademika Pressindo.

Firmansyah, D. (2018). Analysis of Language Skills in Primary School Children (Study Development of Child Psychology of Language). PrimaryEdu - Journal of Primary Education, 2(1), 35-44.

J.S., Badudu. (1992). Cakrawala Bahasa Indonesia II. Jakarta: Gramedia. 
Fadhillah Rahma Purba, Gresia Palentina, Fitriani Lubis...

Lubis Fitriani. (2021). Pendidikan Bahasa Indonesia Untuk Perguruan Tinggi. Medan: Unimed Press.

Muchlis, M. (2014). Garis-garis Besar Tata Bahasa Baku Indonesia. Jakarta: Refika Aditama.

Pranowo. (2015). Teori Pembelajaran Bahasa. Yogyakarta: Pustaka pelajar.

Sugiono. (2015). Metode Penelitian Kuantitatif Kualitatif dan $R \& D$. Bandung: Alfabeta. 